Session 2613

\title{
A Senior Exam to Assess the Learning of Core Competencies in a Chemical Engineering Curriculum
}

\author{
R.E. Terry, W.V. Wilding, and J.N. Harb \\ Department of Chemical Engineering \\ Brigham Young University \\ Provo, Utah 84602
}

\begin{abstract}
The Chemical Engineering Department faculty at Brigham Young University have identified a set of core competencies that we feel provide the foundation for problem solving in chemical engineering. To assist in our assessment of student learning of these core competencies we have developed a Core Competency Exam to be administered during the senior year. One of the observed benefits of the exam is its role in focusing the attention of both students and faculty members on the core elements of our program. The exam also provides a quality check for graduating students, and feedback for program improvement. Our experience to date indicates that the Core Competency Exam, along with other elements of our assessment plan, will have a significant positive impact on the education of our students.
\end{abstract}

\section{Introduction}

As part of our assessment plan, the Chemical Engineering Department faculty at Brigham Young University have defined a set of core competencies that we have designated for mastery by all of our graduating students ${ }^{1}$. The intent of these core competencies is to focus on the fundamental concepts and skills upon which more complicated applications are based. The underlying assumption is that mastery of core concepts will improve the ability of students to reason through and address a broad range of problems, as well as provide a foundation for the solution of complex application problems. The goal is to have every student achieve mastery of the core competencies to the point where their understanding effectively becomes engineering intuition.

A Core Competency Exam has been developed in order to assess the proficiency of our graduating students in the core areas. This exam fulfills several important purposes. First, it represents a requirement for graduation. All students who graduate from our program are expected to demonstrate mastery of the core competencies by passing the exam. Second, it provides feedback to our program on specific competencies and areas where our students may be weak. This feedback provides motivation for curricular and/or pedagogical modifications needed to address the problem(s). Third, the exam emphasizes the importance of the core competencies to our students and faculty. 
Students are keenly aware that retention of knowledge and skills in the core areas is a requirement for graduation. Therefore, they must do more than simply pass their courses. Faculty awareness of the need to help students learn core concepts is also heightened. It is our desire to emphasize the core competencies at all levels of instruction. The presence of a core competency exam helps to accomplish this objective by setting the core competencies apart from other competencies defined for our program.

A description of the development and format of the core competency exam is presented in the next section. This is followed by a section that examines data from the exam. Finally, the results of a student survey on the examination process are reported.

\section{Development of the Exam}

It was necessary to write our own exam in order to achieve the desired benefits mentioned above. In particular, it was critical that the exam be intimately tied to our curriculum by directly addressing the core competencies. Also, development of our own exam permitted us to write conceptually based questions to probe student understanding rather than just their ability to plug numbers into learned relationships. It should be noted that the emphasis on these core competencies is in addition to the focus on the rest of the objectives and attributes of our chemical engineering program which includes those specifically detailed by EC2000.

Table 1 shows the list of 18 core competencies targeted by the exam. One objective in preparing the exam was to determine the minimum number of questions needed to adequately cover these competencies. We hoped to keep the exam short enough so that students could complete it in about 2 hours, although we did not intend to restrict the exam time. Our experience with a pilot exam indicated that we should allow an average of about five minutes per problem. Therefore, we determined that the entire exam should consist of 25 questions. This required use of a single question for the evaluation of most of the 18 competencies, while two questions were used for a few of the competencies and three questions were used for one competency that we chose to emphasize because of its importance.

We envisioned questions that stressed a conceptual understanding whenever possible rather than the ability to simply plug numbers into an equation. We also wanted to minimize common test-taking errors by preparing questions that focused on only one concept and were unambiguous. We determined that a multiple-choice exam was the best format for the exam since this would facilitate the generation of a sufficient quantity of questions, simplify the grading of exams, and facilitate data gathering and processing.

The exam questions were grouped into four rough categories and the faculty was divided into four corresponding groups. Questions were prepared and reviewed to ensure that they focused narrowly on the desired competency and were free of errors and ambiguities. Writing good questions proved to be a daunting task, and it has taken 
several iterations to get to a point of confidence in our ability to do so. Consider the sample question below.

In a flat-plate heat exchanger operating at steady state, a hot liquid flows along one side of a copper plate, while a cool liquid flows along the other side. Conditions are such that the temperatures of the two surfaces of the plate are fixed. If the thickness of the plate is doubled but the temperatures remain the same, the rate of heat transfer through the plate will
(a) double
(b) remain the same
(c) be cut in half
(d) be reduced by the ratio $\ln \left(\mathrm{t}_{\text {initial }} / \mathrm{t}_{\text {final }}\right)$ where $\mathrm{t}=$ thickness

This problem focuses attention on the relationship between the driving force for heat transfer and the resulting transfer. A conceptual understanding of this cause and effect relationship will allow a student to correctly respond to this question. Although the question may appear trivial to an experienced educator, only $61 \%(37 / 61)$ of the students answered it correctly on a pilot exam. Twenty-three percent of the students reported (b) as the answer, indicating a significant fundamental flaw in their understanding. On the other hand, these same students could readily answer a simple quantitative heat transfer problem requiring calculation of the heat transfer rate given a temperature difference by substituting the given quantities into the appropriate relationship without this conceptual understanding. Our hope is that by mastering the core concepts, one of which is illustrated in this example, students will be better able to solve engineering problems.

Our intent is to have every student pass this exam before he or she graduates. The exam is administered early in the senior year. This has been done on paper to date, but we will soon begin using a newly developed, web-based system that generates the exam for each student from the pool of questions. The new system also allows on-line completion of the exam and automatic scoring and recording. This minimizes the manpower required to operate the system. Once a student completes the exam they are given their score and told which competencies (if any) that they did not pass. Then, after a period of a month, they are given a second exam that includes only questions that address the competencies that were missed on their previous attempt. This exam is automatically generated by the web system based on the student's performance on the previous exam. A third exam, similar to the second exam, is administered for any competencies that remain "unmastered" after the second exam. If three tries prove insufficient, then the student is asked to complete some remedial work before an additional exam is administered. The student must pass the exam in order to qualify for his/her B.S. degree in chemical engineering. 
Table 1. Competencies covered by Core Competency Exam.

\begin{tabular}{|c|c|}
\hline Competency & Expectation \\
\hline 3.1 .1 & $\begin{array}{l}\text { Students will be able to: (1) solve problems using both SI and the AES system of } \\
\text { units and; (2) interconvert between unit systems. }\end{array}$ \\
\hline 3.1 .2 & $\begin{array}{l}\text { Students will be able to solve steady-state material balances for single or multiple } \\
\text { process units with or without reactions; and energy balances for single process units } \\
\text { with reaction. }\end{array}$ \\
\hline 3.2 .1 & $\begin{array}{l}\text { Students will be able to identify equilibrium phases on either PT or PV projections of } \\
\text { the PVT surface, and be able to obtain vapor pressures for pure components for a } \\
\text { given temperature. }\end{array}$ \\
\hline 3.3 .1 & $\begin{array}{l}\text { Students will be able to solve the mechanical energy balance for frictionless flow } \\
\text { with and without shaft work. }\end{array}$ \\
\hline 3.3 .2 & $\begin{array}{l}\text { Students will be able to (1) describe qualitatively the physical significance of } \\
\text { viscosity in terms of fluid behavior; (2) define and describe the physical significance } \\
\text { of Re; (3) describe flow regimes that correspond to different values of Re. }\end{array}$ \\
\hline 3.4 .1 & $\begin{array}{l}\text { Students will: (1) be able to assign appropriate modes of HT to a given physical } \\
\text { scenario, (2) know Newton's law of cooling, understand, and be able to use Fourier's } \\
\text { law (1D) and Newton's law of cooling. }\end{array}$ \\
\hline 3.4 .2 & $\begin{array}{l}\text { Students will understand conduction and convection resistances, and be able to use } \\
\mathrm{q}=\Delta \mathrm{T} / \Sigma \text { Res and } \mathrm{q}=\mathrm{UA} \Delta \mathrm{T}_{\mathrm{lm}} \text {. }\end{array}$ \\
\hline 3.4 .3 & $\begin{array}{l}\text { Students will understand } \mathrm{q}=\mathrm{h} \mathrm{A} \Delta \mathrm{T} \text { and qualitatively, how } \mathrm{h} \text { is related to } \mathrm{Nu}, \mathrm{Re} \text {, and } \\
\text { Pr, and how to obtain a value for } \mathrm{h} \text {. }\end{array}$ \\
\hline 3.5 .1 & $\begin{array}{l}\text { Students will understand Fick's law and the contributions to the flux arising from a } \\
\text { driving force and from convection. }\end{array}$ \\
\hline 3.5 .2 & $\begin{array}{l}\text { Students will be able to use the heat/mass transfer analogy to estimate mass transfer } \\
\text { coefficients. }\end{array}$ \\
\hline 3.6 .1 & $\begin{array}{l}\text { Students will understand and be able to use definitions of rate, nth-order rate } \\
\text { expressions, and the Arrhenius temperature dependence } \mathrm{k}=\mathrm{A} \exp (-\mathrm{E} / \mathrm{RT}) \text {. They will } \\
\text { know how to determine } \mathrm{n} \text { and } \mathrm{E} \text { from basic rate data. }\end{array}$ \\
\hline 3.7 .1 & $\begin{array}{l}\text { Students will be able to solve steady-state, first law problems with single process } \\
\text { units. }\end{array}$ \\
\hline 3.7 .2 & $\begin{array}{l}\text { Students will be able to solve bubble and dew problems assuming Raoult's Law } \\
\text { behavior. }\end{array}$ \\
\hline 3.7 .3 & $\begin{array}{l}\text { Students will know how } \Delta \mathrm{G} \text { is related to equilibrium constants and will be able to } \\
\text { calculate an equilibrium constant (from } \Delta \mathrm{G} \text { ) at } 298 \mathrm{~K} \text { and set up law of mass action in } \\
\text { terms of extent of reaction for ideal gas phase reactions. }\end{array}$ \\
\hline 10.1 .1 & $\begin{array}{l}\text { Student will be able to use the design equations for ideal reactors to determine reactor } \\
\text { volume, feed flow rate, or conversion. }\end{array}$ \\
\hline 10.2 .1 & $\begin{array}{l}\text { Students will be able to do preliminary size and performance calculations on shell- } \\
\text { and tube-heat exchangers using the log-mean temperature difference method. }\end{array}$ \\
\hline 10.3 .1 & $\begin{array}{l}\text { Students will be able to determine the power required for a pump to deliver a } \\
\text { specified flow rate of an incompressible fluid through a single pipeline (excludes } \\
\text { flow in parallel lengths) consisting of pipe (multiple diameters acceptable). }\end{array}$ \\
\hline 10.4 .2 & $\begin{array}{l}\text { Students will be able to use Raoult's law and vapor pressure correlations to solve the } \\
\text { VLE and mass balances associated with a single-stage isothermal flash. }\end{array}$ \\
\hline
\end{tabular}




\section{Results}

The core competency exam was given for the first time to a full class of graduating seniors last semester (Fall 2001). Students were required to answer all but two of the questions correctly in order to pass the exam. Table 2 shows pass rate data for the initial full-scale testing of the exam. The average exam score was $21 / 25$, and only about onethird of the students passed the exam on their first attempt. Of these, only six students answered all of the problems correctly. It has been our intention that future versions of the exam would require students to answer $100 \%$ of the questions correctly in order to pass. Hence, the pass rate on the first attempt was considerably lower than what we would like to see. This was not surprising given that we are still learning how to adjust our curriculum and teaching methods in order to facilitate mastery of core competencies. We expect the initial pass rate to improve as we do a better job of addressing the core competencies throughout our program, although it may be necessary to allow students to miss a problem or two until the improvements have been made and demonstrated.

Table 2. Results for Core Competency Exam Administered Fall 2001

\begin{tabular}{|c|c|}
\hline Total Number of Students & 59 \\
\hline Number Passed in $1^{\text {st }}$ Attempt $(\geq 23 / 25)$ & 20 \\
\hline $\begin{array}{c}\text { Number Passed in } 2^{\text {nd }} \text { Attempt }(\leq 2 \\
\text { incorrect answers for competencies not } \\
\left.\text { completed correctly in } 1^{\text {st }} \text { Attempt }\right)\end{array}$ & 33 \\
\hline $\begin{array}{c}\text { Number Passed in } 3^{\text {rd }} \text { Attempt }(\leq 2 \text { incorrect } \\
\text { answers for competencies not completed } \\
\left.\text { correctly in } 1^{\text {st }} \text { and } 2^{\text {nd }} \text { Attempts }\right)\end{array}$ & Not Yet Available \\
\hline
\end{tabular}

It is interesting to examine student performance on the different types of problems included on the competency exam. For example, the exam consisted of both quantitative and qualitative problems. Table 3 shows that the score (average number of students who correctly completed each type of problem) for both the quantitative and qualitative problems was nearly identical, and that the standard deviation was also nearly the same. This would indicate that the students found the qualitative problems to be as challenging as their quantitative counterparts. We believe that this reflects the efforts of our faculty to write qualitative problems that would probe the students' understanding of core concepts and physics. Increased emphasis on conceptual understanding should improve the performance of students on these types of qualitative problems.

Table 3. Qualitative vs. Quantitative Problems

\begin{tabular}{|c|c|c|c|}
\hline $\begin{array}{c}\text { Type of } \\
\text { Problem }\end{array}$ & $\begin{array}{c}\text { Number of } \\
\text { Problems }\end{array}$ & $\begin{array}{c}\text { Average Number of } \\
\text { Correct Responses } \\
(\mathbf{m a x}=\mathbf{5 9})\end{array}$ & $\begin{array}{c}\text { Standard } \\
\text { Deviation }\end{array}$ \\
\hline Quantitative & 15 & 49.1 & 7.0 \\
\hline Qualitative & 10 & 50.1 & 6.0 \\
\hline
\end{tabular}


The average score in different subject areas can be used as a measure of the competency of students in those areas. Figure 1 shows the average score for the problems grouped into traditional chemical engineering subfields. The problem scores for both Material Balances and Thermodynamics were considerably lower than the others; on the average, only $77 \%$ of the students completed a given problem in either of these two areas correctly. This average may not seem low for an exam, but it is much lower than desired given the fact that we are testing core competencies that we expect all of our students to master. We have identified these areas as areas that need attention in our curriculum.

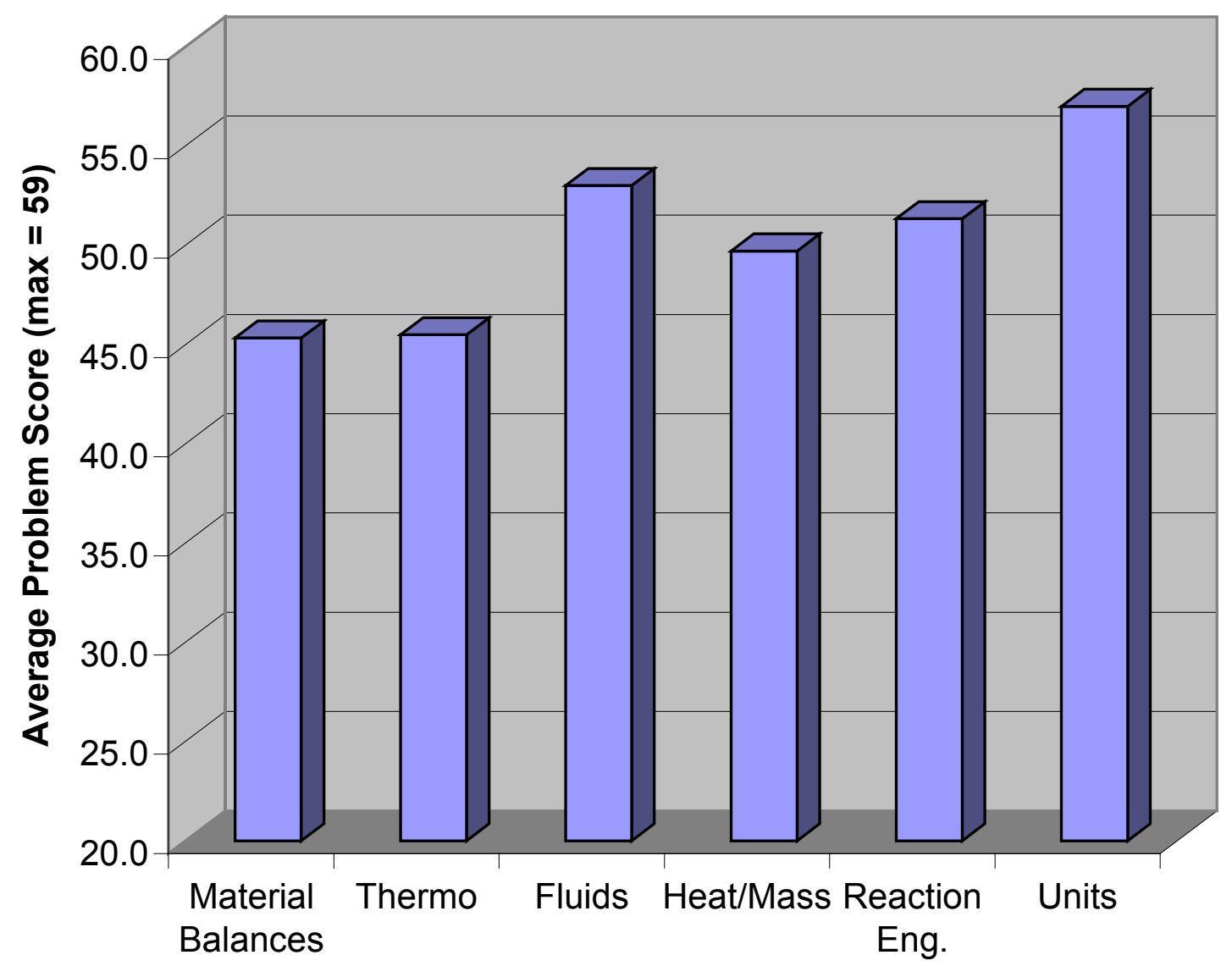

Subject Area

Figure 1. Average Score (average number of students to successfully complete a problem) as a function of subfield.

The pass rate for a given competency is equal to the fraction of students that correctly answer all of the problems associated with that competency. Pass rate data are given in Table 4 for all of the competencies tested. Again, Material Balances and Thermodynamics appear to be our most problematic areas. Note that the low pass rate for Material Balances is due, in part, to the greater number of problems given in this area. While only $49 \%$ of the students completed all 3 problems correctly, an additional $36 \%$ correctly completed 2 out of the 3 problems. However, our goal is mastery of the core 
areas, and more problems in the material balance area were intentionally included because of the high importance attached to this competency for chemical engineers.

Table 4. Pass rate for each competency for initial attempt at competency exam (100\% required to pass competency).

\begin{tabular}{|c|c|c|c|}
\hline Competency & $\begin{array}{c}\text { Number of } \\
\text { Problems }\end{array}$ & ChE Area & $\begin{array}{c}\text { Pass } \\
\text { Rate }\end{array}$ \\
\hline 3.1 .1 & 2 & Units & $93 \%$ \\
\hline 3.1 .2 & 3 & Material Balances & $49 \%$ \\
\hline 3.2 .1 & 1 & Thermo & $69 \%$ \\
\hline 3.3 .1 & 1 & Fluids & $73 \%$ \\
\hline 3.3 .2 & 2 & Fluids & $93 \%$ \\
\hline 3.4 .1 & 1 & Heat/Mass & $88 \%$ \\
\hline 3.5 .1 & 1 & Heat/Mass & $95 \%$ \\
\hline 3.5 .2 & 1 & Heat/Mass & $85 \%$ \\
\hline 10.3 .1 & 1 & Fluids & $93 \%$ \\
\hline 3.4 .2 & 1 & Heat/Mass & $98 \%$ \\
\hline 3.4 .3 & 2 & Heat/Mass & $68 \%$ \\
\hline 3.6 .1 & 2 & Reaction Eng. & $85 \%$ \\
\hline 10.1 .1 & 1 & Reaction Eng. & $78 \%$ \\
\hline 10.2 .1 & 1 & Thermo & $59 \%$ \\
\hline 3.7 .1 & 2 & Thermo & $64 \%$ \\
\hline 3.7 .2 & 1 & Thermo & $85 \%$ \\
\hline 3.7 .3 & 1 & Thermo & $69 \%$ \\
\hline 10.4 .2 & 1 & Thermo & $85 \%$ \\
\hline
\end{tabular}

A comparison was made between the performance on the competency exam and the major GPA of the students who took the exam. The results are shown in Figure 2. This figure shows that students with very high major GPA's are much less likely to perform poorly on the exam. Also, most of the perfect exam scores were for students with high GPA's. However, the results for major GPA's between 3.0 and 3.5 were quite scattered, ranging from a low of 13 to a high of 25 . Clearly, GPA is not a good measure of performance in core competencies for this range of GPA's. Overall, GPA appeared to be weakly correlated to competency exam performance.

\section{Student Feedback}

To obtain student feedback on the exam we conducted a survey following the first retake exam. Table 5 shows the survey and composite student responses. 


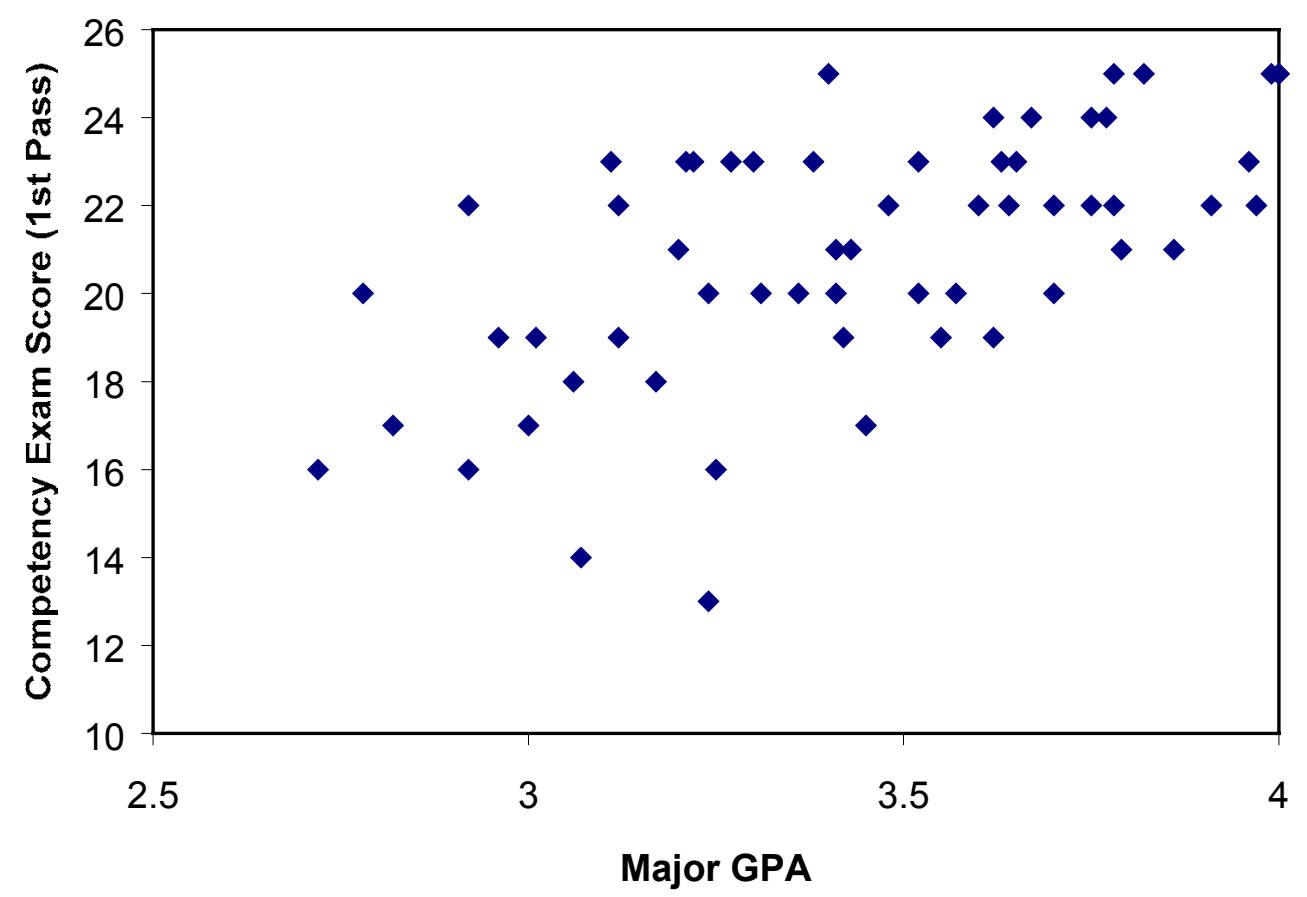

Figure 2. Comparison of Competency Exam Score with Major GPA.

Table 5. Student survey results.

\begin{tabular}{|l|c|c|}
\hline \multicolumn{1}{|c|}{ Survey Statement } & $\begin{array}{l}\text { Average Response: } \\
\text { Likert Scale from 1 to 5 } \\
\text { (1= Mostly disagree; 5 } \\
\text { Mostly agree, NA = do } \\
\text { not have an opinion) }\end{array}$ & $\begin{array}{c}\text { Number } \\
\text { of } \\
\text { Responses }\end{array}$ \\
\hline $\begin{array}{l}\text { 1. The core competency process (inclusion } \\
\text { of competency list in course syllabi, focus } \\
\text { on these in courses, preparing for, taking, } \\
\text { and passing the exam) has enhanced my } \\
\text { ability to solve chemical engineering } \\
\text { problems. }\end{array}$ & 2.9 & 55 \\
\hline $\begin{array}{l}\text { 2. The core competency process (inclusion } \\
\text { of competency list in course syllabi, focus } \\
\text { on these in courses, preparing for, taking, } \\
\text { and passing the exam) has enhanced my } \\
\text { confidence in my ability to solve chemical } \\
\text { engineering problems. }\end{array}$ & & 57 \\
\hline $\begin{array}{l}\text { 3. The core competency exam (not the } \\
\text { entire process) should be a requirement for } \\
\text { graduation. }\end{array}$ & 3.4 & 54 \\
\hline $\begin{array}{l}\text { 4. Graduating seniors should be required to } \\
\text { pass the core competency exam at the 100\% } \\
\text { level within the three available tries. }\end{array}$ & & 5.8 \\
\hline
\end{tabular}

Proceedings of the 2002 American Society for Engineering Education Annual Conference \& Exposition Copyright (C) 2002, American Society for Engineering Education 
Student responses indicate that they perceive only a modest contribution of the exam to their ability to solve engineering problems and to their confidence in doing so. These students have not had the benefit of having the focus on the core competencies throughout their education, since this focus was implemented during their junior year, and we hope and expect that students in future years will have a better appreciation for the process. Students generally agree that passing the competency exam is a good requirement for graduation. One student commented, "If we fail that test, we shouldn't graduate." Additional comments from students are shown in Table 6. Students generally believe that a passing mark of $100 \%$ is too high of a requirement.

Students were also asked how much time they spent preparing for the exam and we were surprised to see their response of 3.1 hours (on average). This probably indicates that either they did not see a need to study, or that they were deterred by the enormity of the task of reviewing material from three years worth of coursework.

\section{Summary and Conclusions}

A Core Competency Exam for assessing student proficiency in core competencies has been developed for use in the Department of Chemical Engineering at Brigham Young University. The exam consists of 25 questions written by the faculty to address specific competencies.

Exam results indicate that students have not mastered core competencies to the desired level. Only a third of the students passed the exam on the first attempt, even when they were allowed to miss two of the 25 problems. Particular weaknesses in the areas of thermodynamics and material balances were also suggested by the exam. Students perceive only a modest contribution of the exam to their ability to and confidence in solving engineering problems; however, these students have not had the benefit of a strong focus on the core competencies throughout their education.

One of the observed benefits of the exam is its role in focusing the attention of both students and faculty members on the core elements of our program. The exam also provides a quality check for graduating students, and feedback for program improvement. Our experience to date indicates that the Core Competency Exam, along with other elements of our assessment plan, will have a significant positive impact on the education of our students.

\section{Reference}

1. R.E. Terry, J.N. Harb, W.C. Hecker, and W.V. Wilding, "Definition of Student Competencies and Development of an Educational Plan to Assess Student Mastery Level," Special Issue of IJEE on Assessment, in press, 2002. 
Table 6. Selected Comments from Students

I thought the exam this year was a very good test of knowledge. I think a packet of review materials might be helpful.

- I don't really feel like this test received proper focus in terms of related class' homework assignments, tests, etc.

- I also don't think a $100 \%$ requirement is the right criterion to use.

Eliminating any time limit on the exam was an excellent move.

I think the exam was a good measure of overall engineering skills that should be required to graduate.

I actually think using the FE exam would be a better way to go because it would give students the confidence that they've learned not only what the BYU ChemE dept. feels we should learn but also what the rest of the profession feels we should learn. I also think it's good that the FE reviews broader (but still important to every engineer) concepts.

It seems to me like it's just another hoop to jump through. If we want to impress the ABET group, teach the material a little better!

I think a high, but not a $100 \%$ level, is good. Some people have different test taking abilities, but can still solve problems. I liked proving to myself I can be an engineer. Everyone should be able to pass the exam and I feel we were well prepared for the exam. It might be easier to take the exam in parts, so we aren't really tired of thinking by the end of the test. SHOULD BE ABLE TO SEE WHAT MISSED - don't know what we're doing wrong.

To me, the competency process didn't help much throughout my Chem E education. In most classes we would get a competency sheet at the beginning of the semester, then never talk about it again till we filled out evaluation sheets at the end of semester. Incorporate more into classes.

Exam was good because it showed me how much I knew.

I don't think anybody really studied the competencies when it is first handed out in the beginning class. The test itself gave me confidence that $I$ have the abilities needed to go out and work. I think the classes we take and normal exams are more then enough, and I don't think the test is needed. It is better however than a standardized test would be though.

The concept of requiring a core competency exam is completely sound and the way it was administered here was reasonable. I certainly would not relax any of the standards, and I might even make it a bit more stringent.

I think the competencies are good for teachers - so they know what to emphasize in class. 


\section{RONALD E. TERRY}

Ron Terry is a Professor of Chemical Engineering at Brigham Young University. He has conducted scholarly work and published numerous articles in engineering education. He is an active member of the ERM Division within ASEE. He holds B.S. and Ph.D. degrees in Chemical Engineering from Oregon State University and Brigham Young University, respectively.

\section{W. VINCENT WILDING}

Vincent Wilding is an Associate Professor of Chemical Engineering at Brigham Young University. His research interests include thermophysical properties, phase equilibria and environmental engineering. He received his B.S. degree in Chemical Engineering from Brigham Young University in 1981 and his Ph.D. in Chemical Engineering from Rice University in 1985.

\section{JOHN N. HARB}

John Harb is a Professor of Chemical Engineering at BYU. He received his Ph.D. from the University of Illinois at Urbana in 1988. He has been active in ASEE and has written several papers and a monograph related to engineering education, as well as a textbook for first-year chemical engineering students. He conducts research in electrochemical engineering where he is developing microscopic batteries for use with MEMS. 